\title{
Colapso induzido pelo exercício em um Labrador Retriever
}

\author{
Exercise-induced collapse in a Labrador Retriever
}

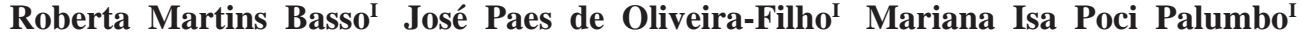
Luiza Stachewski Zakia ${ }^{I}$ João Pessoa Araújo Júnior ${ }^{I I}$ Alexandre Secorun Borges ${ }^{I I I}$
\end{abstract}

\section{- NOTA -}

RESUMO

O colapso induzido pelo exercício (EIC) é uma enfermidade hereditária caracterizada por fraqueza muscular dificuldade de locomoção e colapso após atividade física intensa. Esta enfermidade autossômica recessiva afeta principalmente cães jovens da raça Labrador Retriever e decorre da mutação c.767G>T no gene codificador da proteína dinamina 1 (DNM1). O objetivo deste trabalho é relatar o primeiro caso de EIC em Labrador Retriever no Brasil. O teste molecular para detectar a mutação responsável pela EIC confirmou o diagnóstico clínico em um Labrador Retriever com histórico de fraqueza muscular e colapso após exercício. Uma vez diagnosticada no Brasil, ressaltase a importância de inserir a EIC entre os diagnósticos diferenciais das enfermidades neuromusculares em cães da raça Labrador Retriever e utilizar o diagnóstico molecular para orientar os acasalamentos.

Palavras-chave: exercício, mutação, cães, sequenciamento, DNM1.

\section{ABSTRACT}

The exercise-induced collapse (EIC) is a hereditary disease characterized by muscle weakness, impaired locomotion and collapse after intense exercise. This autossomic recessive disorder affects mainly Labrador Retriever presenting the mutation c.767G $>$ T in the dynamin 1 (DNM1) gene. The objective of this study is to report the first case of exercise-induced collapse in Labrador Retriever in Brazil. The molecular test detected the specific genetic mutation and confirmed the clinical diagnosis in a Labrador Retriever with clinical history of weakness and collapse after exercise. It is important to include this disease as part of the differential diagnosis of neuromuscular diseases in Labrador Retriever and use the molecular test to guide matings.

Key words: exercise, mutation, dogs, sequencing, DNM1.
O colapso induzido pelo exercício (EIC) é uma enfermidade hereditária autossômica recessiva diagnosticada com maior frequência em cães da raça Labrador Retriever (TAYLOR et al., 2008; MINOR et al., 2011), sendo considerada a causa mais comum para a intolerância ao exercício em cães jovens dessa raça nos EUA (TAYLOR et al., 2008). A EIC é decorrente da mutação c.767G> T no gene codificador da proteína dinamina 1 (DNM1) (PATTERSON et al., 2008), a qual é responsável pela reciclagem das vesículas sinápticas nos terminais nervosos durante um estímulo persistente e de alta frequência (FERGUSON et al., 2007). Esta mutação resulta na substituição de uma arginina por uma leucina, o que leva a uma anormalidade da transmissão sináptica pela diminuição da correta tradução da proteína dinamina 1, afetando, portanto, a função normal do sistema nervoso (FERGUSON et al., 2007; PATTERSON et al., 2008).

Já foi observada mutação responsável da EIC em cães das raças Chesapeake Bay Retriever e Curly-Coated Retriever, as quais possuem alta relação de parentesco com a raça Labrador Retriever (PATTERSON et al., 2008). Além dessas, outras raças, como Boykin Spaniel, Pembroke Welsh Corgi e os mestiços da raça Labrador Retriever, já foram citadas carreando a mutação relacionada à EIC (MINOR et al., 2011). Labradores Retrievers homozigotos para a mutação c.767G>T no gene DNM1 são clinicamente normais em repouso, mas apresentam colapso após 5

\footnotetext{
IFaculdade de Medicina Veterinária e Zootecnia (FMVZ), Universidade Estadual Paulista “Júlio de Mesquita Filho” (Unesp), Botucatu, SP, Brasil.

IIInstituto de Biociências de Botucatu (IBB), Unesp, Botucatu, SP, Brasil.

IIIDepartamento de Clínica Veterinária, Faculdade de Medicina Veterinária e Zootecnia (FMVZ), Unesp, Distrito de Rubião Junior, s/n, 18618-970, Botucatu, SP, Brasil. E-mail: asborges@fmvz.unesp.br. Autor para correspondência. Recebido 21.11.13 Aprovado 24.02.14 Devolvido pelo autor 28.04.14 CR-2013-1549.R1
} 
a 20 minutos de exercício intenso (PATTERSON et al., 2008; TAYLOR et al., 2009; MINOR et al., 2011). Em estudo conduzido por TAYLOR et al. (2008), sete (7/335) cães morreram durante os episódios de colapso.

O diagnóstico de EIC é sugerido pela exclusão de outras doenças relacionadas ao colapso e à intolerância ao exercício (TAYLOR et al., 2008). Entretanto, o diagnóstico específico da EIC só é possível com a detecção da mutação em testes moleculares (MINOR et al., 2011). Considerando que o EIC é comumente diagnosticado em cães da raça Labrador Retriever em outros países, o objetivo deste trabalho é relatar o primeiro caso desta doença no Brasil e alertar veterinários e criadores sobre a importância da realização de testes moleculares para diagnóstico desta enfermidade nos animais desta raça que serão utilizados na reprodução.

Foi encaminhado ao Hospital Veterinário da Faculdade de Medicina Veterinária e Zootecnia de Botucatu, Unesp, um canino da raça Labrador Retriever, macho, com coloração do pelame caramelo, de dois anos de idade, com histórico de fraqueza dos membros posteriores durante atividades intensas de caminhada. O animal já havia apresentado quatro crises semelhantes, sendo que o primeiro episódio ocorreu quando o animal iniciou atividades de adestramento, com aproximadamente um ano de idade. Todos os episódios apresentados pelo animal foram semelhantes, e incluíam fraqueza progressiva dos membros posteriores que evoluía até a incapacidade de ambulação. O quadro iniciava após aproximadamente 20 minutos de exercício físico e era mais frequente em dias com a temperatura mais elevada. Durante a crise, o animal não apresentava alterações no nível de consciência. Após o colapso, o animal ficava em repouso e se recuperava em algumas horas. $\mathrm{O}$ animal estava em bom estado geral e nenhuma queixa adicional foi relatada durante a anamnese.

Durante o exame físico, todos os parâmetros avaliados estavam dentro dos valores de normalidade. Os exames ortopédico e neurológico não revelaram nenhuma alteração. Além disso, no momento da avaliação, o animal correu e pulou normalmente, sem paresia, ataxia ou indício de dor articular. Foi realizado hemograma completo e análises bioquímicas (ureia, creatinina, proteína total, albumina, globulina, GGT, FA, ALT), sendo que todos os resultados apresentavam-se normais.

O diagnóstico final de EIC foi feito pelo Laboratório de Biologia Molecular do Departamento de Clínica Veterinária, FMVZ - Unesp -Botucatu. O processo de extração de DNA sanguíneo foi realizado com o kit Illustra Blood GenomicPrep Mini Spin
Kit (GE Healthcare). A concentração e pureza do DNA obtido foram avaliadas por espectrofotometria utilizando o Nanodrop ${ }^{\circledR} 2000$ (Thermo Scientific ${ }^{\mathrm{TM}}$ ). A PCR foi realizada utilizando "primers", previamente descritos por PATTERSON et al. (2008), que amplificam um fragmento de 337 pares de bases, incluindo todo o exon 6 do gene DNM1. Controles negativos da reação foram realizados utilizando água. Os produtos da PCR com o tamanho correto estimado após corrida eletroforética em gel de agarose a 1,5\% corada com Gelred ${ }^{\circledR}$ (Biotium ${ }^{\circledR}$ ) foram submetidos ao sequenciamento direto, utilizando BigDye ${ }^{\circledR}$ Terminator v3.1 Cycle Sequencing (Applied Biosystems $^{\mathrm{TM}}$ ). As sequências e eletroferogramas obtidos foram analisadas no programa Sequencher ${ }^{\mathrm{TM}}$ 5.1. (Gene $\operatorname{Codes}^{\odot}$ ) e alinhadas e comparadas à sequência do RNAm Canis lupus familiaris dynamin 1 (DNM1) normal com a ferramenta disponível em http://blast.ncbi.nlm.nih.gov.

$\mathrm{O}$ teste genético comprovou que o animal apresentava o alelo mutado em homozigose. Após o diagnóstico, nenhum tratamento medicamentoso foi prescrito, apenas foi recomendada a diminuição da intensidade dos exercícios e que eles não fossem realizados nos períodos mais quentes do dia.

Casos da síndrome do colapso induzido pelo exercício são comumente observados em outros países (TAYLOR et al., 2008; MINOR et al., 2011) e estudos descrevem até $4,5 \%$ de homozigotos (PATTERSON et al., 2008; TAKANOSU et al., 2012). Assim como o animal deste relato, a maioria dos cães portadores da síndrome apresenta os primeiros sinais clínicos com idade inferior a quatro anos (MINOR et al., 2011). Embora a doença tenha ocorrido em um macho com coloração do pelame caramelo, a EIC não tem predileção por sexo ou coloração do pelo (TAYLOR et al., 2008).

A realização de exercícios intensos, acompanhados de grande agitação e excitação do animal, parecem facilitar o desencadeamento do colapso (TAYLOR et al., 2009). Os sinais clínicos apresentados pelo Labrador deste caso são compatíveis com os descritos na literatura. Os animais portadores da síndrome são normais em repouso, mas, depois de 5 a 20 minutos de intensa atividade física, desenvolvem paraparesia flácida não dolorosa, que pode evoluir para colapso (TAYLOR et al., 2009). Assim como observado neste relato, a recuperação após colapso na grande maioria dos casos é gradual, ocorrendo ao longo de 5 a 45 minutos (TAYLOR et al., 2008). Entretanto, alguns animais podem vir a óbito durante a crise (TAYLOR et al., 2008; FURROW et al., 2013). A maioria dos cães afetados não apresenta 
alterações no nível de consciência durante o colapso, contudo, no trabalho de TAYLOR et al. (2008), os proprietários observaram algum grau de alteração mental em 23\% dos cães afetados. Estes autores alertam sobre a importância clínica desta síndrome, uma vez que 3\% dos casos observados foram fatais.

Segundo STEISS et al. (2004), há a possibilidade de que o aumento de temperatura corporal e a alcalose respiratória após exercício em cães de competição da raça Labrador Retriever estejam relacionados com o desencadeamento do colapso. Há a hipótese de que temperaturas corporais altas, atingidas durante exercício intenso, contribuam para uma disfunção na proteína mutante, gerando, assim, falhas na transmissão sináptica, desencadeando os sinais da enfermidade (MATWICHUK et al., 1999; TAYLOR et al., 2009). O animal deste relato não foi avaliado durante o colapso, assim, não existem dados sobre sua temperatura corporal ou possíveis alterações metabólicas neste momento.

Como a restrição dos exercícios físicos intensos diminuiu drasticamente os episódios de colapso ou até mesmo provocou o total desaparecimento desses episódios na maioria dos animais (TAYLOR et al., 2008) e na ausência de tratamento específico para a doença, o proprietário do animal deste relato foi apenas orientado, visando a diminuir a frequência das crises, a não realizar exercícios durante os períodos mais quentes do dia e suspender a atividade física assim que os primeiros sinais de incoordenação motora se tornarem aparentes.

O diagnóstico molecular da mutação responsável pela EIC já foi realizado utilizando a PCR associada a enzimas de restrição (PATTERSON et al., 2008) e por uma PCR alelo-específica (TAKANOSU et al., 2012). Neste relato, optou-se pelo sequenciamento direto de produtos de PCR, utilizando os primers previamente descritos por PATTERSON et al. (2008). Esta metodologia, além de apresentar um bom custobenefício, mostrou-se eficiente para realização do diagnóstico. A comprovação molecular da mutação responsável pela EIC neste caso aponta a necessidade de inserir esta enfermidade entre os diagnósticos diferenciais das enfermidades neuromusculares em cães da raça Labrador Retriever no Brasil. Além disso, reforça que é importante os criadores desta raça avaliarem se a mutação está presente em seus cães, para direcionamento dos acasalamentos.

\section{AGRADECIMENTOS}

Os autores agradecem a Fundação de Amparo à Pesquisa do Estado de São Paulo (FAPESP, Processo 2013/03076-8.) pela bolsa de Iniciação Científica do primeiro autor.

\section{COMITÊ DE ÉTICA E BIOSSEGURANÇA}

Aprovado pela Câmara de Ética em Experimentação Animal (Processo no 24/2013).

\section{REFERÊNCIAS}

FERGUSON, S.M. et al. A selective activity-dependent requirement for dynamin 1 in synaptic vesicle endocytosis. Science, v.316, p.570-574, 2007. Disponível em: <http://www. sciencemag.org/ content/316/5824/570.full>. Acesso em: 20 nov. 2013. doi: $10.1126 /$ science. 1140621 .

FURROW, E. et al. Relationship between dynamin 1 mutation status and characteristics of recurrent episodes of exercise-induced collapse in Labrador Retrievers. Journal of the American Veterinary Medical Association, v.242, n.6, p.786-791, 2013. Disponível em: <http://avmajournals. avma.org/doi/abs/10.2460/ javma.242.6.786?url_ver=Z39.88-2003\&rfr_id=ori:rid:crossref. org\&rfr_dat $=$ cr_pub\%3dpubmed $>$. Acesso em: 20 nov. 2013. doi: 10.2460/javma.242.6.786.

MATWICHUK, C.L. et al. Changes in rectal temperature and hematologic, biochemical, blood gas, and acid-base values in healthy Labrador retrievers before and after strenuous exercise. American Journal of Veterinary Research, v.60, n.1, p.8892, 1999. Disponível em: <http://vetneuromuscular. ucsd.edu/ cases/2000/media/labrador.pdf>. Acesso em: 20 nov. 2013.

MINOR, K.M. et al. Presence and impact of the exercise-induced collapse associated DNM1 mutation in Labrador retrievers and other breeds. Veterinary Journal, v.189, p.214-219, 2011. Disponível em: <http://www.sciencedirect.com/science/article/pii/ S109002331100236X>. Acesso em: 20 nov. 2013. doi: 10.1016/j. tvj1.2011.06.022.

PATTERSON, E. et al. A canine DNM1 mutation is highly associated with the syndrome of exercise-induced collapse. Nature Genetics, v.40, n.10, p.1235-1239, 2008. Disponível em: <http://www.nature.com/ng/journal/v40/n10/abs/ng.224.html>. Acesso em: 20 nov. 2013. doi:10.1038/ng.224.

STEISS, J. et al. Physiologic responses in healthy Labrador Retrievers during field trial training and competition. Journal of Veterinary Internal Medicine, v.18, p.147151, 2004. Disponível em: <http://onlinelibrary.wiley.com/ doi/10.1111/j.1939-1676.2004.tb00153.x/abstract>. Acesso em: 20 nov. 2013. doi: 10.1111/j.1939-1676.2004.tb00153.x.

TAKANOSU, M. et al. Genotyping of exercise-induced collapse in Labrador retrievers using an allele-specific PCR. Veterinary Journal, v.193, n.1, p.293-295, 2012. Disponível em: <http:// www.sciencedirect.com/science/article/pii/S1090023311004035>. Acesso em: 20 nov. 2013. doi: 10.1016/j.tvjl.2011.10.018.

TAYLOR, S.M. et al. Exercise-induced collapse of Labrador retrievers: survey results and preliminary investigation of heritability. Journal of American Animal Hospital Association, v.44, n.6, p.295-301, 2008. Disponível em: <http://www.jaaha.org/ content/44/6/295.short>. Acesso em: 20 nov. 2013.

TAYLOR, S.M. et al. Evaluations of Labrador retrievers with exercise-induced collapse, including response to a standardized strenuous exercise protocol. Journal of American Animal Hospital Association, v.45, n.1, p.3-13, 2009. Disponível em: <http://www. jaaha.org/content/ 45/1/3.full>. Acesso em: 20 nov. 2013. 